\title{
Effect of surface roughness on neutral and dense gas dispersion in the BLWT
}

\author{
P. Michálek \& D. Zacho \\ Department of Aerodynamics, VZLU, Aerospace Research and \\ Test Establishment, Prague, Czech Republic
}

\begin{abstract}
Measurements of neutral and dense gas dispersion in a boundary layer wind tunnel with different surface roughness were performed. Neutral or dense gas was emitted from a small "quasi-point" source located in the wind tunnel floor. This "quasi-point" source represents leakages of gases from small industrial plants in the urban area. The tunnel surface was either covered with uniform roughness or with a smooth surface in order to create a significant difference in the boundary layer mean velocity profile and turbulence intensity. Also influence of plume momentum on vertical and horizontal distribution of tracer gas concentration above the source was studied. Both neutral and dense gases were marked with tracer gas (ethane) and concentrations were measured with a comb probe connected to four flame ionization detectors (FID). Results have shown that plume momentum significantly affects plume shape. Boundary layer turbulence intensity also affected plume behavior, but to a lesser degree than plume momentum.

Keywords: gas dispersion, quasi-point emission source, surface roughness, $B L W T$.
\end{abstract}

\section{Introduction}

Air pollution has become a serious problem in the last few decades. Due to a large amount of industrial chemical plants, which use many dangerous chemical substances, there may occur and sometimes really occurs a leakage of different gases. The modelling of non-buoyant or dense gas dispersion in the air in case of accidents or terrorist attacks is therefore important from the point of view of population protection, because non-buoyant and dense gases disperse near the land surface, thus these gases may threaten human life and health. The process of 
dispersion is relevant for firemen and rescue services, so that they could estimate the progress of harmful gas dispersion and size of the contaminated area. Following wind tunnel experiments will help to verify boundary conditions for the development of software that will be capable of calculating the progress of gas dispersion within the urban area in chosen locations. Experimental verification of gas dispersion between buildings in the boundary layer wind tunnel is required for the development of this software. This experiment of surface roughness dependence on gas dispersion in a boundary layer wind tunnel (BLWT) presents a part of a research project focused on creating this computational tool for utilization in the Czech Republic. The software will use 3D maps including potential gas release locations and an actual meteorological situation as input data to estimate the immediate size of the contaminated area with harmful gases.

\section{Boundary layer wind tunnel and simulation system}

The boundary layer wind tunnel (BLWT) has been in operation in VZLU since 1996. Its design and construction was realized with the cooperation of VZLU, a.s. and Czech Technical University in Prague, Klokner Institute under promotion of Grant Agency of the Czech Republic. The working part of the wind tunnel is $15.6 \mathrm{~m}$ long and $1.8 \times 1.5 \mathrm{~m}$ in a cross-section. The fan with $1.8 \mathrm{~m}$ diameter is powered by a $55 \mathrm{~kW}$ DC motor that generates the maximal wind speed $25 \mathrm{~m} / \mathrm{s}$ above the boundary layer. Equilibrium boundary layers have been adjusted for three types of terrain consequently (agricultural, suburban and urban) consistent with Eurocode 1 roughness categories. Instrumentation in the tunnel has been extended and actualized during the entire period of the BLWT operation with expansion in the field of structural dynamics and gas dispersion modeling. This includes a computer controlled hot-wire anemometer and pressure scanners, particle image velocimeter (PIV), a hydrocarbon tracing and detecting system with flame ionization detectors (FID) and visualization means. A computer controlled turntable position with $1750 \mathrm{~mm}$ in diameter and XYZ traversing mechanism are used for the change of wind direction and moving with the probes. Static pressure along all the working parts is monitored on 14 cross sections during adjustment its optimal distribution by ceiling contour changes. In front of the test section there are two independent fixed probes for measuring velocity above the boundary layer. This includes a Pitot-static probe and hotwire Dantec Steel Clad Transducer 54T28 probe. The fan RPM is controlled with digital engine revolution-counter and computer output. Atmospheric conditions (i.e. temperature, relative humidity and barometric pressure) are recorded in a computer via a Vaisala PTU100 probe located under the exit part of the tunnel.

The model space is accessible from both sides through windows sized $1620 \mathrm{x}$ $960 \mathrm{~mm}$. The entire working section is equipped with a movable ceiling contour for longitudinal static pressure gradients elimination. Pressure in the working section is monitored in 14 sections, in which the ceiling is suspended. Four of these pressure taps belong to the model section, where it is possible to set the ceiling height while the tunnel is operating (e.g. in the case when the front model 
area is significantly changing with wind direction) to avoid excessive wind tunnel blockage. Other pressure taps are located near before and beyond the tunnel fan in order to measure the pressure difference of the tunnel fan. A schematic diagram of the BLWT in VZLU is shown in Fig. 1.

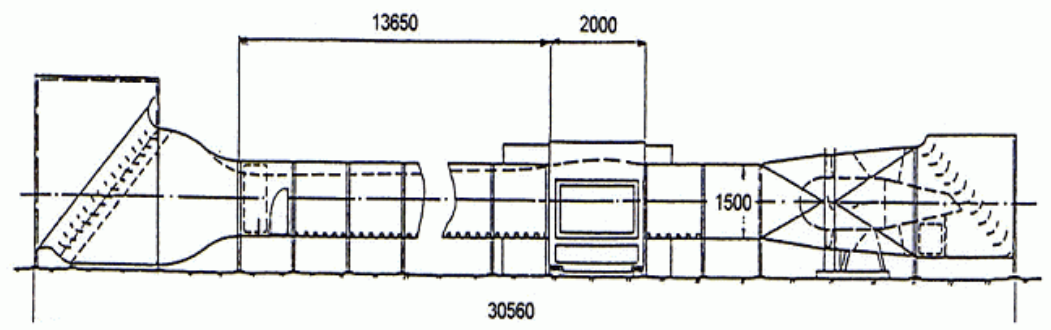

Figure 1: $\quad$ Scheme of BLWT in VZLU.

The BLWT in VZLU was equipped with devices for experiments with tracer gas (ethane) in the year 2000. Since then many experiments with tracer gas have been performed, e.g. heavy gas dispersion studies by Ulman et al. [1] and Ulman [2], pressure and concentration measurements on a 3D model building for inlet and outlet optimisation by Jirsak et al. [3], air infiltration into model building by Michálek and Zacho [4] and gas leakage from a railway station inside an urban area by Ulman et al. [5] and also simulation of chimney plumes by Jirsak and Ulman [6].

\subsection{Modelling the wind profile}

The incoming boundary layer must have first of all fully developed turbulent flow corresponding to the flow in the Earth's atmosphere. In order to check this condition, the so-called Reynolds roughness number Re* exists. This value decides the minimal operation velocity of the BLWT no matter for the model properties. This condition for similarity with atmospheric boundary layer (ABL) is stated in ASCE Report No.67 [7] as $\mathrm{z}_{0} \mathrm{u}^{*} / \mathrm{v} \geq 2,5$, where $\mathrm{z}_{0}$ is aerodynamic roughness length $(\mathrm{m}), \mathrm{u}^{*}$ is friction velocity $(\mathrm{m} / \mathrm{s})$ and $v$ cinematic viscosity of air $\left(\mathrm{m}^{2} / \mathrm{s}\right)$. For the purpose of gas dispersion modeling this condition can be relaxed up to $\mathrm{Re}^{*} \geq 1,0$. For velocities above the boundary layer ca. $4 \mathrm{~m} / \mathrm{s}$ and more this minimal Reynolds roughness number criterion is satisfied.

The turbulent boundary layer structure is created with a rectangular barrier $140 \mathrm{~mm}$ high at the beginning of the test section and with a roughness field made of an insulation sheet with $7 \mathrm{~mm}$ high truncated cones, which contributes to create a fully developed turbulent boundary layer entering the model section. These means create turbulent boundary layer corresponding to the 3rd terrain roughness category (forests and suburban areas) according to Eurocode 1.

The cause of non-stationary effects during flow around bluff bodies is not only the vortex structure of incoming flow, but also the structure in wake due to flow separation at the downwind side of the building. The non-stationary flow field around a bluff body immersed in atmospheric boundary layer (ABL) depends on the roughness level, body geometry, size, angle of wind attack on the 
bluff body and flow regime, which changes with velocity. Boundary layer modeling requires good attention while modeling in reduced scale in order to ensure the results of transferring from model to full size could be possible. Since there were no model buildings in this experiment, the condition of minimal building Reynolds number was irrelevant.

\subsection{Changes in surface roughness}

In order to create significant changes of velocity profiles and turbulence intensity between a smooth and rough surface, the last part of the test section with a roughness field $122 \mathrm{~cm}$ long was removed and replaced with a wooden board with a smooth surface. Hereby a $2.2 \mathrm{~m}$ long part of the tunnel floor upwind the emission source was provided with a smooth surface. The other part of the tunnel test section remained unchanged with a roughness field made of a plastic sheet with $7 \mathrm{~mm}$ high truncated cones. On the contrary, to make a longer rough surface, half of the model section floor $(1 \mathrm{~m})$ upwind the source was covered with the same plastic sheet with cones, so that the roughness field made a continuous field from the beginning of the test section up to the emission source in the centre of the model section. These two roughness adjustments created changes of mean velocity profiles and turbulence intensity, as can be seen in Fig. 2. These measurements were performed with a hot-wire anemometer Dantec Streamline with a single wire probe and measured in the centre of the model section (above the source location) in both cases. U stands for mean velocity in $\mathrm{m} / \mathrm{s}$ at height $\mathrm{z}$ in $\mathrm{mm}$ and Iu means intensity of turbulence in percent.

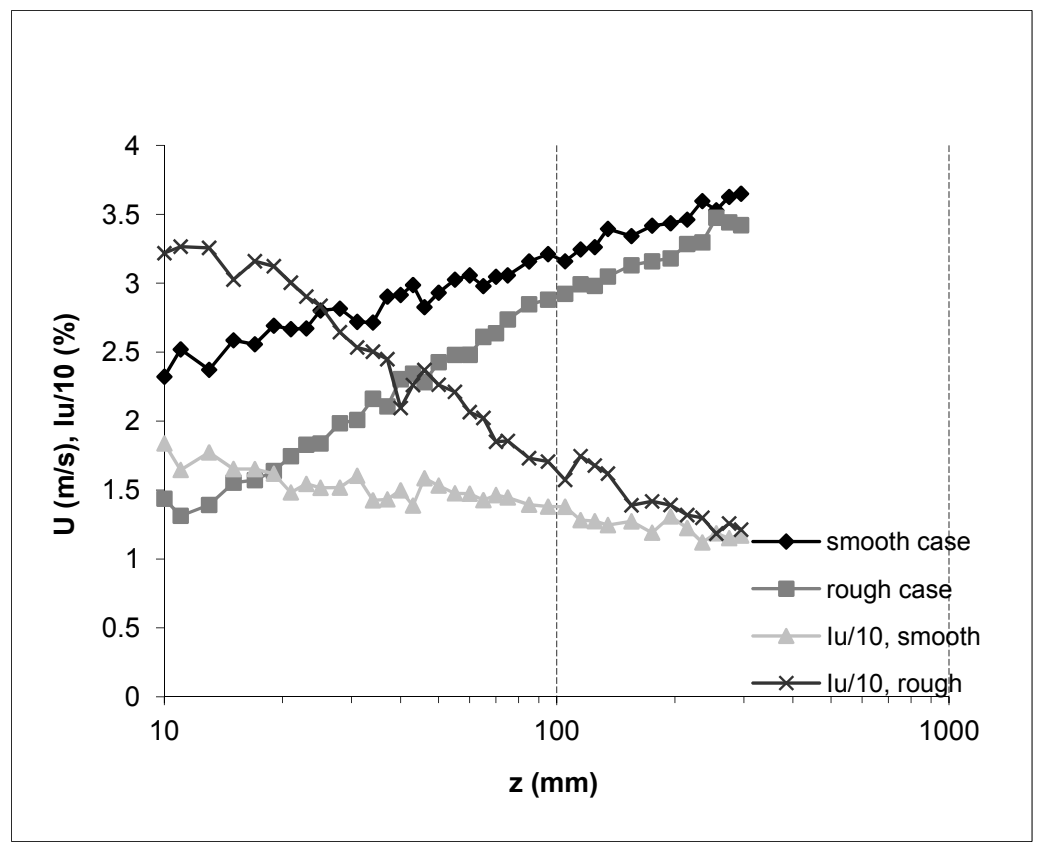

Figure 2: Boundary layer velocity profiles. 


\section{Performance of the experiment}

A so-called "quasi-point source" for emitting gases into the wind tunnel was used. This source consists of a small chamber sized $30 \times 30 \times 10 \mathrm{~mm}$ whose one side of rectangular size $25 \times 25 \mathrm{~mm}$ was covered with porous fabric used in aircondition filters. This topside of the source is placed in the wind tunnel floor level. This fabric in the source allows slowing down gas emission velocity, therefore the emission exit velocity is much lower than ambient flow velocity. This feature is important e.g. for traffic emission modeling or some slow industrial emissions that do not emit into the atmosphere through stacks. This quasi-point source is designated for measuring the dispersion of emissions near this source, i.e. distances of tens to hundreds of meters from the source in full scale. This source was designed for the purpose of studying near field gas dispersion in an urban area, thus this source presents some small industrial plant or some gas tank, which may produce slow gas releases. The gas inlet into the source is located under the source chamber, which lies under the white square in the wind tunnel floor. The source located in the wind tunnel floor and comb probe above it is presented in Fig. 3.

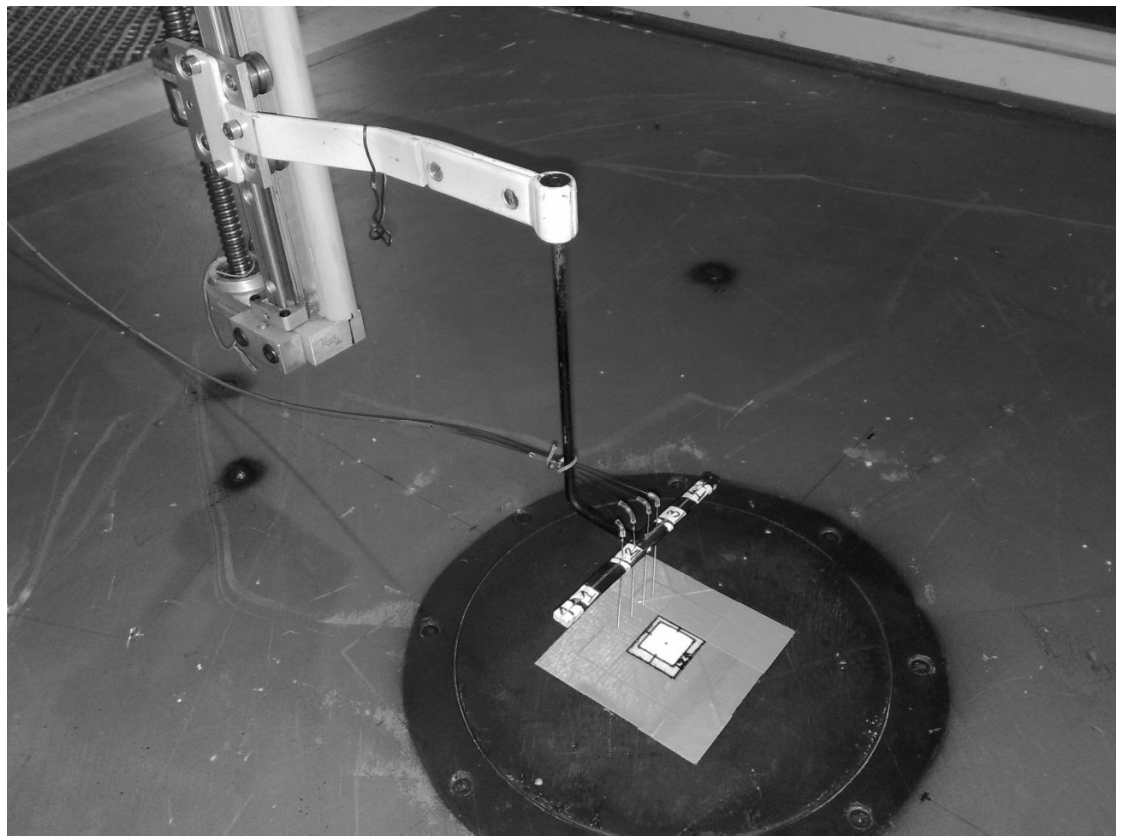

Figure 3: $\quad$ Point source in BLWT model section - smooth surface case.

The tracer gas (ethane) was dosaged with a rotameter Aalborg and air or sulfur hexafluoride with electronic flow controller Alicat Scientific. Ethane was dosaged in a volume ca. $3.53 \mathrm{ml} / \mathrm{min}$, air in a volume $1.6-2.21 / \mathrm{min}$ or sulfur hexafluoride $\left(\mathrm{SF}_{6}\right)$ in a volume 1.2-2.2 1/min, according to the required emission momentum. Then the gases were mixed together and released into the tube 
leading to the point source in the wind tunnel floor. For tracer gas concentration measuring we used four flame ionisation detectors FID-80 with EL-980 electrometers. The gas samples were taken with a comb probe with four inlet tubes, which were connected through a capillary tube Fused-Silica with $0.53 \mathrm{~mm}$ internal diameter and ca. $0.5 \mathrm{~m}$ long to a peristaltic pump and then to a FID-80 detector unit. Continually flowing sample changes hydrogen flame ionisation, which is indicated with an electrometer unit and then upon calibration conversed into concentration and recorded in a computer. The FID calibration was made with calibration gas from the Messer Technogas company with a concentration $100 \mathrm{ppm}$ of ethane in air. In this arrangement the frequency response of this measuring chain is up to $10 \mathrm{~Hz}$. The sampling frequency was $100 \mathrm{~Hz}$ in this case. The comb probe was mounted on a traversing mechanism, so that one could measure in various places. Considering the time of dispersion process, which is less than $2 \mathrm{~s}$ from source to comb probe, the effect of ethane and air or $\mathrm{SF}_{6}$ separation is negligible. $\mathrm{SF}_{6}$ is a non-toxic and non-flammable gas with density 5.1-times bigger than air at normal conditions. It is used mainly as an insulation gas in high voltage devices.

Two basic gas mixtures were used, namely air with ethane for modeling of the neutral buoyant emission and $\mathrm{SF}_{6}$ with ethane for dense emission modeling. In order to create different emission momentum, a different volume flow of air or $\mathrm{SF}_{6}$ was used. Less air or $\mathrm{SF}_{6}$ volume flux with the same ethane flux causes bigger ethane concentration and smaller emission momentum, and vice versa. $\mathrm{SF}_{6}$ thanks to a bigger density than air has bigger momentum than air within the same volume flux.

\section{Measured results and discussion}

In order to obtain concentration entering the point source, the source supply tube was connected directly into the probe and initial concentration $\mathrm{C}_{0}$ in ppm was measured. Then the supply tube was connected back to the source and the comb probe was mounted on the traversing mechanism. All four individual suction inlets in the probe were spaced $10 \mathrm{~mm}$ between each other. Then the area above the source of length $32.5 \mathrm{~mm}$, width $30 \mathrm{~mm}$ and height 1 to $14 \mathrm{~mm}$ above the source outlet was measured. A sampling time of $60 \mathrm{~s}$ for one point and waiting $15 \mathrm{~s}$ between moving to the next point were used. Velocity above the boundary layer was set to $4 \mathrm{~m} / \mathrm{s}$.

Data analysis and graphic workspace software Origin 8 was used for displaying measured results and creating contour graphs. Horizontal (XY) and vertical (XZ) concentration contour graphs were plotted. Tracer gas concentrations were transformed into dimensionless concentration $\mathrm{C} / \mathrm{C}_{0}$. Fig. 4 and subsequent present contour graphs of vertical (XZ plane) concentration profiles for dense and neutral gas emission on the smooth and rough wind tunnel surface. The centre of the source is located at coordinates $(0,0)$ and the wind direction is from right to left.

Isoconcentration lines of dense gas dispersion on a smooth surface are presented in Fig. 4 and with a rough surface in Fig. 5. The comparison between 


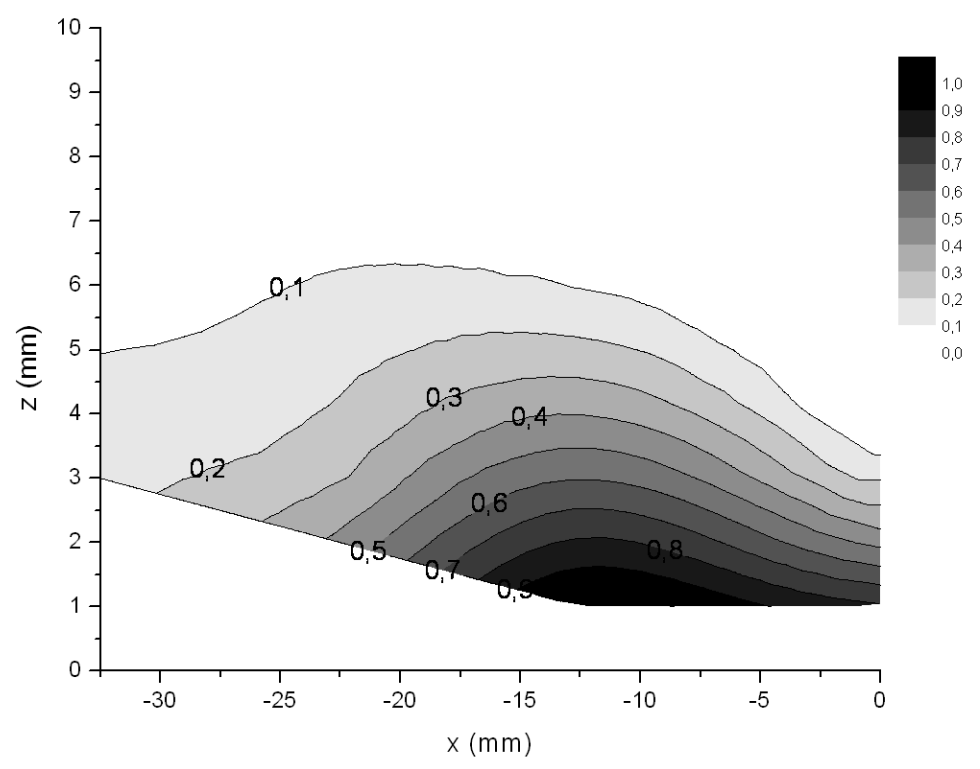

Figure 4: Isoconcentration lines for dense gas dispersion on the smooth surface.

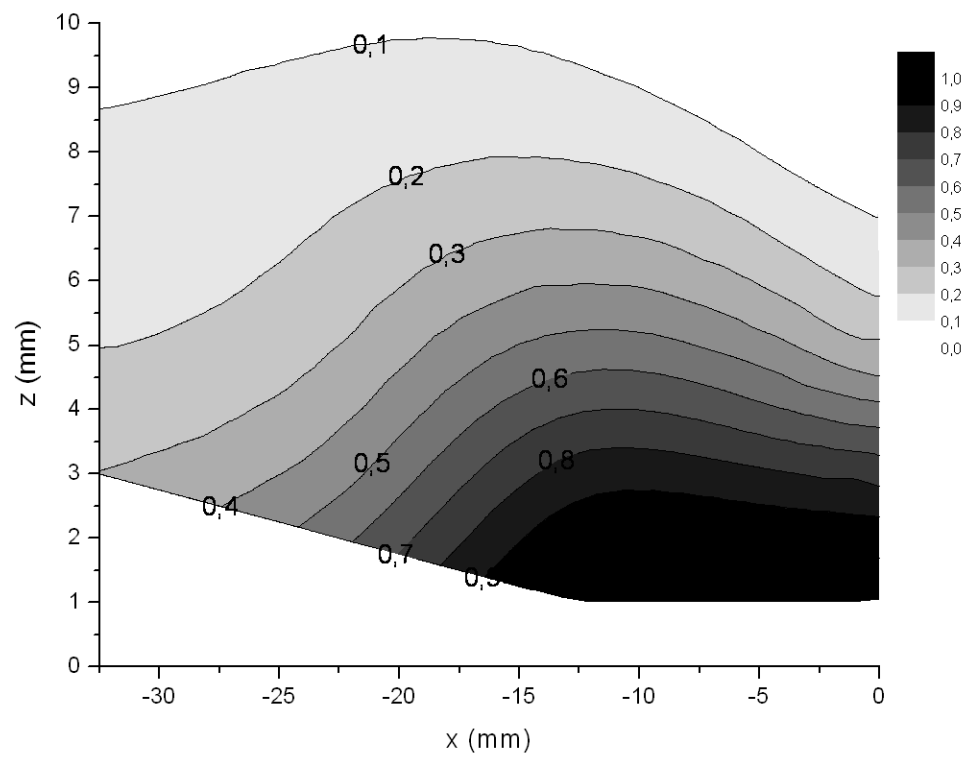

Figure 5: Isoconcentration lines for dense gas dispersion on a rough surface. 
Figs. 4 and 5 is evident; that the higher intensity of turbulence causes the plume to spread higher. The plume momentum is almost the same in these cases.

Figures 6 and 7 show isoconcentration lines for neutral (non-buoyant and non-dense) gas emission dispersion on a rough surface. It is obvious, that in this case the rough tunnel surface and therefore bigger turbulence intensity causes the plume to spread higher as well, but lower than for dense gas emission.

For the purpose of comparison of different variations of the experiment, heights of isoconcentration line $\mathrm{C} / \mathrm{C}_{0}=0.3$ at $\mathrm{x}=0, \mathrm{y}=0$ (source centre) and maximum value of $\mathrm{C} / \mathrm{C}_{0}=0.3$ height over the entire measurement area were plotted into point charts. These charts are presented in Figs. 8 and 9, where p1 stands for bigger and p2 for smaller plume momentum, ps for source emission momentum a pa for ambient flow momentum in $\mathrm{kg} \cdot \mathrm{m}^{-1} \cdot \mathrm{s}^{-2}$. The ambient flow momentum was calculated for unit volume and for height $\mathrm{z}=10 \mathrm{~m}$ in full scale, which means $28.6 \mathrm{~mm}$ in scale 1:350. The source plume momentum was calculated according to source gas inlet volume flux and source area. Figures 8 and 9 indicate that for a source to ambient flow relation up to $10 \%$ the plume spread remains approximately the same and for higher relation (higher plume momentum) i.e. for dense gas emission on a rough surface is the plume spreading higher.

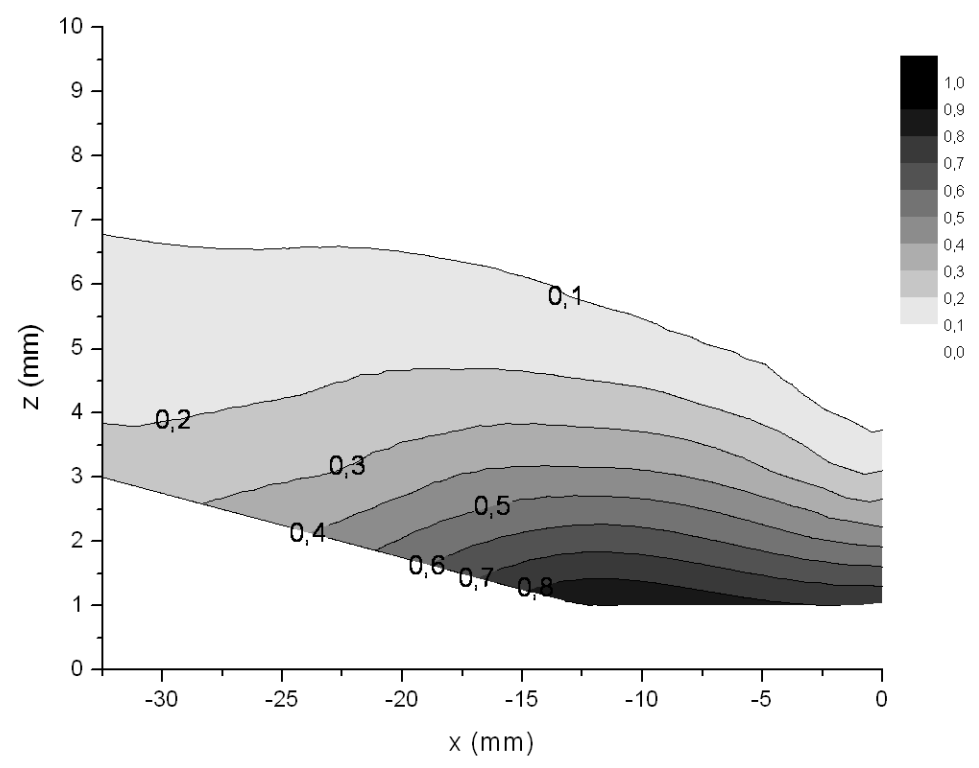

Figure 6: Isoconcentration lines for neutral gas dispersion on a rough surface. 


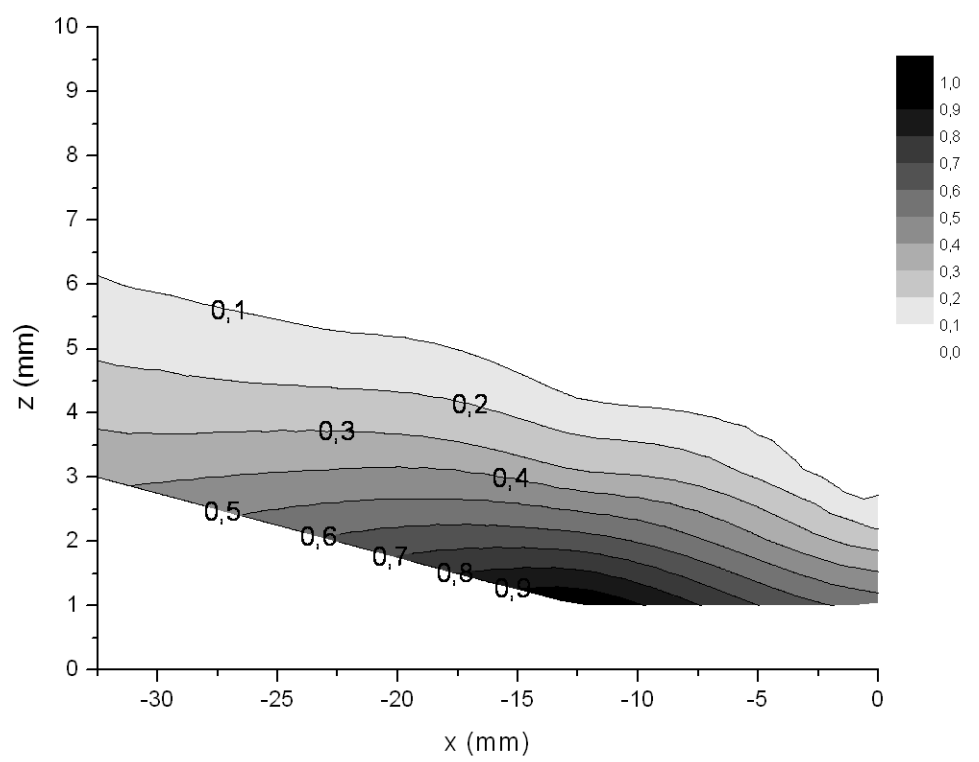

Figure 7: Isoconcentration lines for neutral gas dispersion on a smooth surface.

Plume margins $(\mathrm{C} / \mathrm{CO}=0,3)$ at $\mathrm{x}=0$ (above source center)

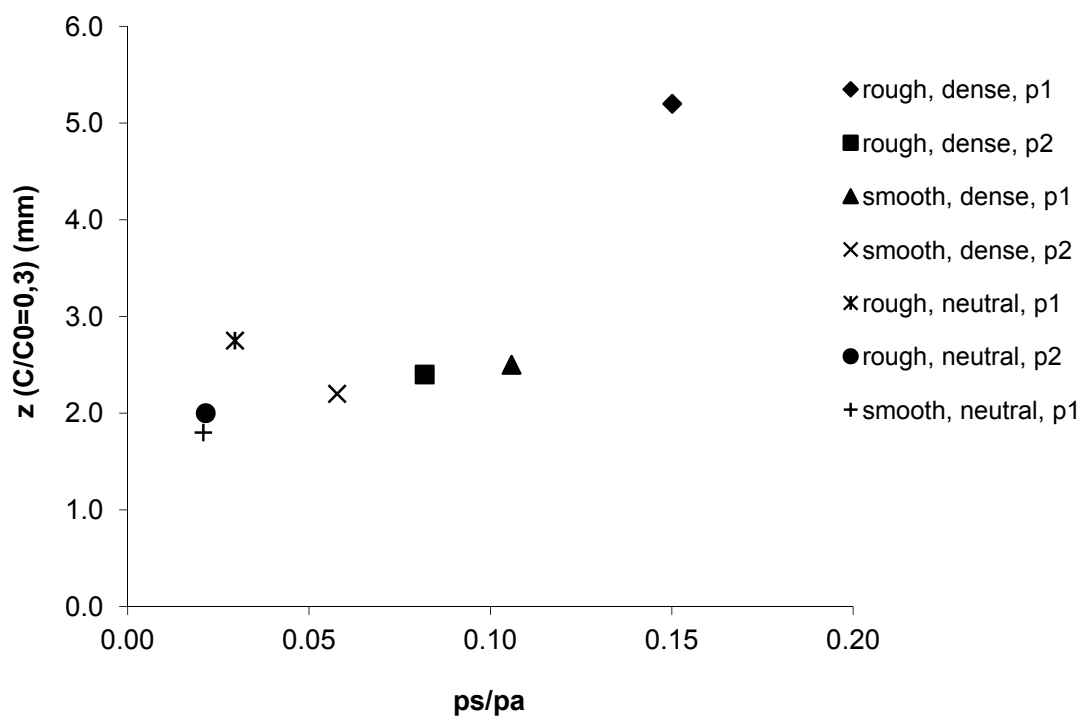

Figure 8: Plume margins above the source center. 


\section{Maximum plume margins $\mathrm{z}_{\max }(\mathrm{C} / \mathrm{CO}=0,3)$}

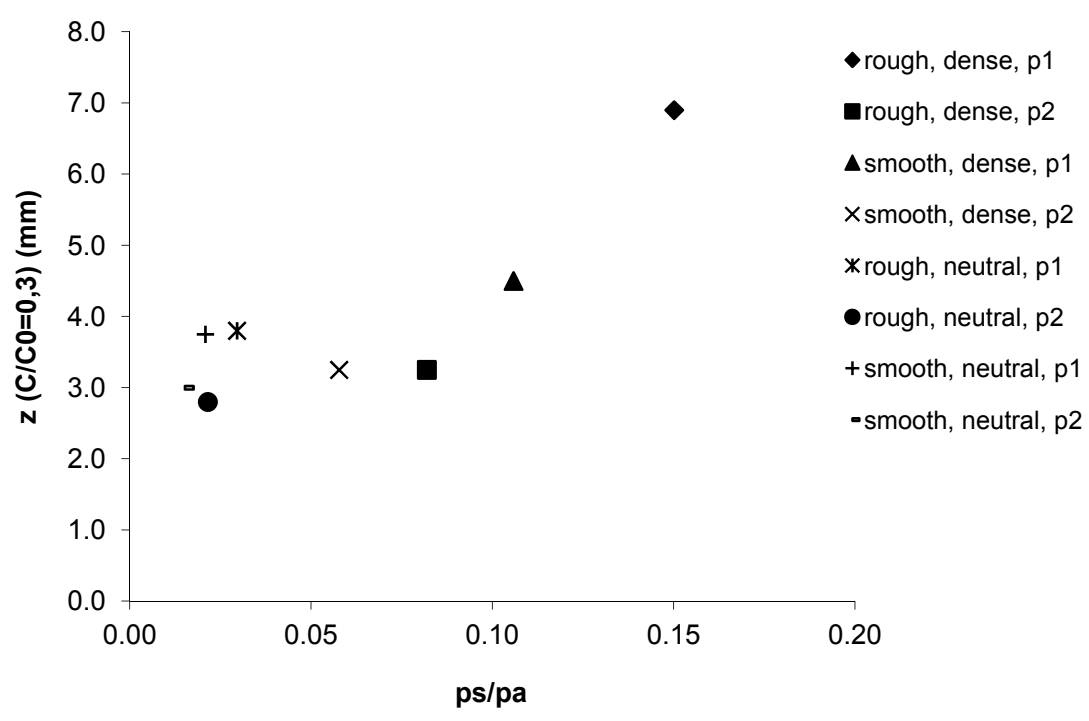

Figure 9: $\quad$ Maximum plume margins.

\section{Conclusions}

The effect of surface roughness of the BLWT floor on neutral buoyant and dense gas dispersion from a point source was investigated. The influence of emission momentum on neutral buoyant and dense gas dispersion was tested too. Measured results showed that surface roughness and resulting turbulence intensity influences gas dispersion in a significant way. Attention was paid to the near vicinity of the modelled emission source. It was observed that due to higher turbulence intensity the rate of dispersion into higher parts of the boundary layer was faster. Higher sulphur hexafluoride density caused in this case higher initial emission momentum. Figures 4 to 7 showed that higher momentum caused more significant transport of emission into higher parts of the boundary layer close to the source. In order to simulate a small point source and observe the pollution in its close environment, it is necessary to reduce the source momentum up to ca. $10 \%$ of incoming ambient flow momentum.

Further research will be focused at gas dispersion farther away from the source and near a single building and group of buildings.

\section{Acknowledgement}

This work was supported by VZLU institutional research project VENT IP3106 funded by Ministry of Industry and Trade of the Czech Republic. 


\section{References}

[1] Ulman R., Drbohlav J., Zachoval D., Dispersion of Harmful Gas Inside Urban Area. Proceedings of $7^{\text {th }}$ UK Conference on Wind Engineering, eds. I. Taylor and M. Vezza, Glasgow, pp.201-204, 2006.

[2] Ulman R., Physical modeling of heavy gas dispersion inside urban area. VZLU report Nr. R-4837, Prague, 2010.

[3] Jirsak M. et al., Tlaková a koncentrační měření na modelu 3D budovy k optimalizaci umístění vstupů a výstupů (in Czech). VZLU report $N r$. $R-4029$, Prague, 2006.

[4] Michálek P., Zacho D., Měření nízkých infiltračních průtoků na 3D modelu budovy (in Czech). VZLU report Nr. R-4846, Prague, 2010.

[5] Ulman R., Janour Z., Sedenkova H., Drbohlav J., The physical modeling of gas dispersion in topographically complicated terrain. Proceedings of EACWE4, eds. J. Náprstek and C. Fischer, Paper No.189, Prague, 2005.

[6] Jirsak M., Ulman R., Chimney plumes simulation in the boundary layer wind tunnel. Advances in Air Pollution Series XI, WIT Press, 2003.

[7] Wind tunnel studies of buildings and structures, ASCE Manuals and Reports on Engineering Practice No.67, N. Isyumov (ed.), Virginia, 1999. 